Sir,

\section{Dacryoendoscopic detection for origin of congenital lacrimal sac fistula}

A 2-year-old Japanese girl complained of tears draining from the skin between her left eye and nose. Examination revealed a single minute orifice located $1 \mathrm{~mm}$ medial and $2 \mathrm{~mm}$ inferior to the left medial canthus (Figure 1a). There was no past history of systemic disease, trauma, eyelid surgery, or any relevant family history.

Initially, dacryoendoscopic observation was performed under general anaesthesia. The dacryoendoscope could not be inserted because the proximal part of the upper canaliculus was partially obstructed. Therefore, we probed the upper canaliculus with a Bowman probe to enable clear observation. There was no aperture into the lacrimal canaliculus. However, an aperture was observed
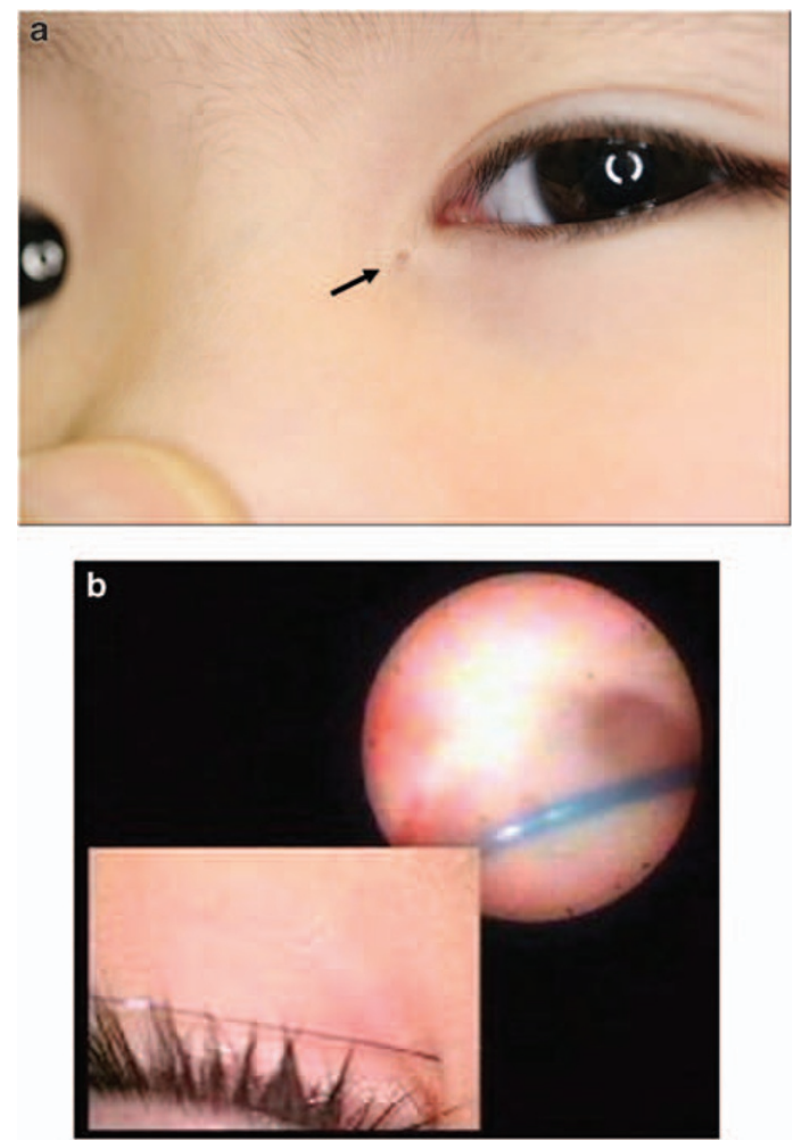

Figure 1 Patient data. (a) Facial photograph. A single minute skin orifice is located $1 \mathrm{~mm}$ medial and $2 \mathrm{~mm}$ inferior to the left medial canthus (arrow). Tear drains and a few fine hairs protrude from the skin orifice. (b) Dacryoendoscopic findings (upper right, dacryoendoscopic photograph; lower left, facial photograph. Facial photograph: lower, cranial; left, temporal). The lacrimal sac aperture is observed in the anterosuperior side near the junction of the common canaliculus and sac. A 7-0 nylon suture, inserted from the skin orifice, can be confirmed as going out from the sac aperture. in the anterosuperior side of the sac near the inner opening of the common canaliculus. We inserted a 7-0 nylon thread from the skin orifice that passed into the sac through the fistula track (Figure 1b). Although the nasolacrimal duct was obstructed, we probed with the tip of the dacryoendoscope and placed a silicone tube. The fistula was dissected and traced to its origin as a core, and then we ligated its base and then completely excised it.

The silicone tube was removed 3 months after the operation. One year after the operation, the patient showed no symptoms.

A congenital lacrimal sac fistula, with an abnormal connection from the skin to the lacrimal passage, is a rare developmental disorder. Fistulae originate mainly from the common canaliculus and occasionally in the lacrimal sac $^{1}$ and they are detected by dacryocystogram, ${ }^{1}$ computed tomography, insertion of a probe into the skin opening, ${ }^{3}$ and polyvinyl siloxane casts. ${ }^{4}$ However, these procedures are frequently inaccurate and/or invasive.

Dacryoendoscopy enables the clear and direct observation of the lacrimal passage by a procedure similar to probing. ${ }^{5}$ The procedure does not require invasive manipulations such as incisions to the skin or nasal mucosa. ${ }^{4}$ Furthermore, we could simultaneously treat the nasolacrimal duct obstruction, which sometimes presents in cases of congenital fistula, ${ }^{1}$ with the tip of the instrument. This case suggested that the dacryoendoscope efficiently and accurately enables the detection of a fistula origin and can also be utilized for the treatment of congenital lacrimal sac fistula.

\section{References}

1 Welham RA, Bates AK, Stasior GO. Congenital lacrimal fistula. Eye 1992; 6: 211-214.

2 Anderson SR, Wesley RE. CT scan of cutaneous lacrimal (anlage) fistula. Ophthalmic Surg 1988; 19: 202-203.

3 Yanagida T, Shima H, Kawasaki K, Matsubara F. Congenital fistulas of the lacrimal sac. Jpn J Ophthalmol 1988; 32: 26-30.

4 Bhatnagar A, Eckstein LA, Douglas RS, Goldberg RA. Congenital lacrimal sac fistula: intraoperative visualization by polyvinyl siloxane cast. Ophthal Plast Reconstr Surg 2008; 24: $158-160$.

5 Sasaki T, Nagata Y, Sugiyama K. Nasolacrimal duct obstruction classified by dacryoendoscopy and treated with inferior meatal dacryorhinotomy. Part I: Positional diagnosis of primary nasolacrimal duct obstruction with dacryoendoscope. Am J Ophthalmol 2005; 140: 1065-1069.

T Yamada, N Katori, Y Takahashi and T Kashima

Department of Oculoplastic and Orbital Surgery, Seirei Hamamatsu Hospital, Shizuoka, Japan

E-mail: prdft318@ybb.ne.jp

The authors have no financial interest related to this manuscript.

Eye (2009) 23, 1871; doi:10.1038/eye.2008.368; published online 16 January 2009 